\title{
IMPROVING BUSINESS ORGANIZATION THROUGH THE IMPLEMENTATION OF INTEGRATED IS
}

\author{
STOJKIC, Z[eljko] \& MAJSTOROVIC, I[van]
}

\begin{abstract}
This paper presents an overview of the concept of introducing an information system with simultaneous reorganization of the company. The aim of the concept is to initiate organizational changes in the company through the implementation of the information system. The implementation of the concept is also aimed to achieve greater transparency in the process, to reduce costs and to increase the level of utilisation of integrated information systems. Keywords: Information system / ERP /PPS /CRM
\end{abstract}

\section{INTRODUCTION}

A synonym for a successful organisation of a production company in the late nineties was a processoriented reorganisation of all flows. This has become a regular practice for large companies, and now it also becomes the obligation for small and medium-sized companies.

Company management system (ERP/PPS) is a tool for managing and tracking orders through the process in production companies. Introducing ERP/PPS system must be simultaneously applied and used to create a better organised structure. These changes will create the basis for long-term survival of the company. Today more and more production companies allocate money for different types of software packages, as well as for systems in production planning and control. Very often the term ERP/PPS is presented in a negative light. This is primarily because the introduction of a system for production planning and control does not provide benefits that were expected from it. For this reason it is necessary to find a concept for process-oriented introduction of a system for production planning and management.

This concept should improve: quality, effectiveness and transparency of the introduction of these systems in companies. It is necessary to reach instant results which should be brought by a new information system and to achieve rapid return on investment. On the other hand, problem in the implementation of integrated information systems is their complexity. Target groups of this concept are production companies which want to achieve effect of rationalisation and more transparency in the process itself through the introduction of a new information system. Through the analysis they may perform also necessary adjustments to the existing organisational flows.

\section{BUSINESS PROCESSES}

Changes are necessary in order to contribute to the improvement of business. These changes in business processes are reflected through:
- business process automation,

- process improvement,

- cooperation (outsourcing),

- complete change of business activities

The subject of this study was to improve business processes through automation and to improve business processes using information technology. Michael E. Porter was the first who started focusing on business processes. In his book "Competitive Advantage: Creating and Sustaining Superior Performance" (1985) he shows concept of a company as a value chain. According to Porter's concept, the value chain consists of primary and secondary activities (processes). Primary activities are those which start purchasing for the needs of production, continue with the production, storage and distribution, marketing and sale, and end up supporting customer after the sale, while each of these activities create certain value for the company. Focusing on business processes culminated after release of articles by Michael Hammer "Reengineering Work: Don't Automate, Obliterate" (1990) and Thomas Davenport and James Short "The New Industrial Engineering: Information Technology and Business Process Redesign" (1990), and books: "Process Innovation: Reengineering Work through Information Technology" [8] and "Reengineering the Corporation: A Manifesto for Business Revolution" [9].

The first wave of launching reengineering projects covers the period from the beginning to the mid 90-ies of the last century, when most companies in developed countries implemented reengineering projects. Research conducted on 180 companies in the USA and 100 companies in Europe has shown that as many as 75 percent of them were included in the BPR (Business Process Reengineering) project in the period from 1993 to 1996. Positive side of these projects was the orientation to internal business processes of companies and not to their functions (offices, departments, jobs) and their optimisation any more, as well as understanding the importance of information technology for the success of business processes. Studies have also shown that in this period more than 50 percent of reengineering projects in the USA and about 70 percent of projects in Europe failed. The second wave of changes in companies refers to the period from 1996 to present, and it's most important features are: partial change or innovation of existing business processes, smaller extent of change, change of fundamental central processes of companies and focusing on external business processes [7]. An important characteristic of the second wave of change is increasing the success rate of projects (about 65 percent in the USA and about 50 percent in Europe), and in line with changes in the concept of reengineering new names 
are created: Business Process Improvement, Business Process Innovation, Business Process Restructuring, Business Process Redesign and Business Process Networking. Since all concepts are aimed at changes, a name that reflects common goal is used today: Business Process Change - BPC.

\section{INTEGRATED INFORMATION SYSTEMS}

Modern information system must serve different but inter-related parts of a business system, such as: business, decision making and management, communication and collaboration. This means that modern information system includes and connects transaction processing system. It supports regular operations and decision support system that supports all levels of management as well as system for communication and collaboration which can use information from all parts of information system, and at the same time it generates data and information to support communication and collaboration. Such an information system integrates its parts into a harmonious hole so we talk about a complete integrated information system.

The principal advantage of this system is that the data of business processes are well connected to each other, or integrated, so in that way functional and process connection within the organisation is very easy to acquire and it is possible to effectively manage and decide by areas, as well as on the level of the whole system. Fig. 1 shows these relations. At the bottom of this model of integrated IS, as a help to the operational level, there is transaction processing system. At higher levels it builds on the system for decision support, and the entire information system is imbued by the system for communication and collaboration. Modern program solution has at its core ERP system with many interrelated program modules that cover data processing of individual business (functional) areas. If the program module covers the entire function, it extends through all levels of organisational management: operational, tactical and strategic.

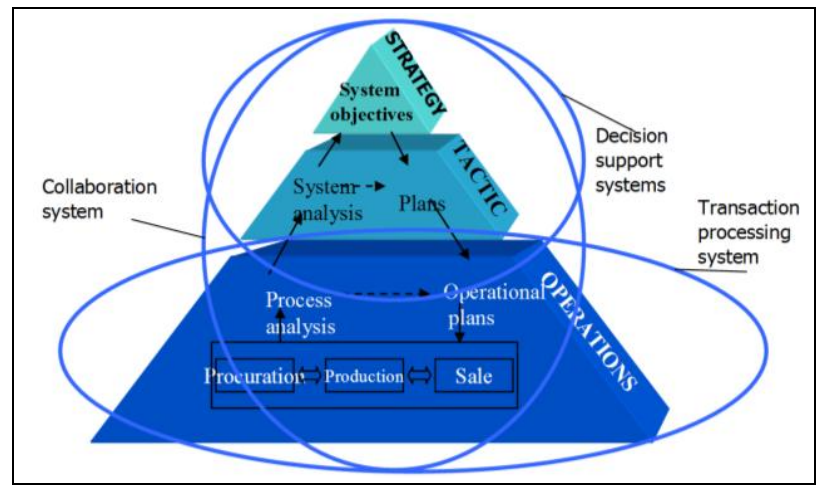

Fig. 1. Model of an integrated information system of a company

Program modules that cover data processing of individual functions, as in the functional organisation, are on the Fig. 1 shown through the examples of three basic functions: procurement, production and sales. They extend vertically through the presented pyramid. In recent years, the ERP systems are upgraded by program modules for performing analytical processing of data specific for data storing, or decision support systems, so we talk about enterprise systems ES as complete operational and analytical program solutions. A connection between performing tasks at the lowest level of function (for example: performing transactional retailing) and data analysis and presentation of the information for decision making at higher levels (for example: reports on the analysis of sale for the CEO) is achieved in completely integrated information system that is vertically integrated. In horizontally integrated information system business process can be systematically monitored.

For example, once you get a purchase order, the information system can take it, pass it 'automatically' to the sales and deliver service that will deliver the goods to the customers. It will send receipt to his information system, possibly open credit on sold goods. The amount of goods supplied will be recorded in the storage register. If the goods need to be produced in the plant, a work order to produce the required quantities of goods will be issued. In the production part of the information system a production plan can be made and computer can conduct process of production. The effects of sale manager can monitor and analyse through information system.

Comprehensive integrated information system provides a record of all business activities. It ensures that data can be effectively used and analysed within the entire organisation. In modern business, information systems of different organisation are trying to connect, and in that way 'to automate' mutual cooperation. That cooperation can be very different. In simple cases it is electronic exchange of data between two information systems, and in more complex situations the exchange of transaction between two systems and real connecting two systems, or creating networked or virtual organisations.

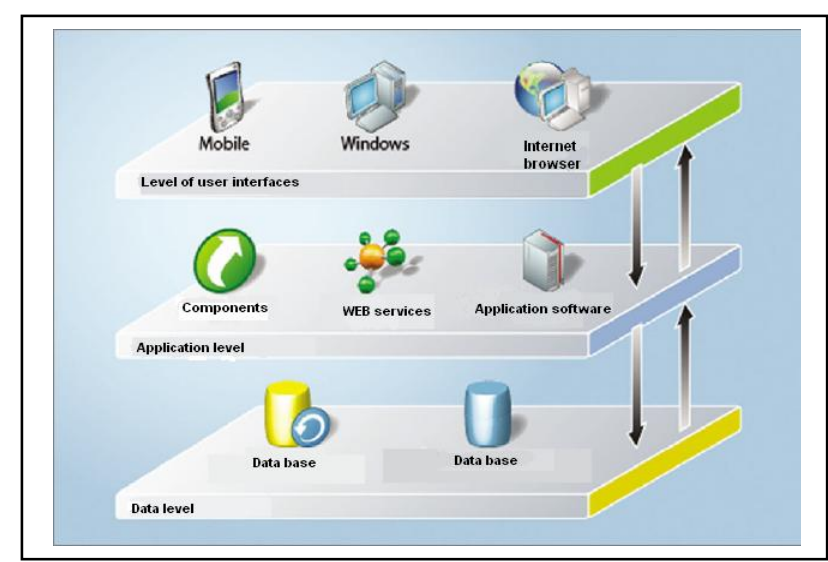

Fig. 2. Three-layer application architecture

In addition to this current state of development of integrated information systems, and thanks to the development of information technology and the development of the concept of three-layer application architecture (Fig. 2.), new concepts of the development of integrated information systems have been developed. A new concept for the development of integrated information systems is going in the direction of serviceoriented application (SOA). SOA concept is a response to the problems and deficiencies caused by existing development of integrated information systems.

One definition of the concept of SOA is that it presents a paradigm of structuring and using of distributed functionalities used by various owners. 
Central content of all definitions are services which are: encircled units and can be used independently, which are available within network, which are independent of program platform and which dynamically integrate inside the system depending on the time of use of certain service.

\section{IMPLEMENTATION OF AN INTEGRATED INFORMATION SYSTEM IN COMPANIES}

Implementation of an integrated information system in companies presents a very significant project for the company. Such a project is not only a significant engagement of resources necessary for business but also a significant risk to the economic success of the project. For this reason it is necessary to pay special attention to the planning of these projects.

The beginning is in the choice of strategy for the implementation of the project. Basically there are two possible strategies for implementation:

- phasing,

- Simultaneous introduction.

Beside the choice of strategy and standard success factors of a project, a significant impact on the outcome of the project has:

- Type of the chosen program solution in terms of

○ functionality of the program solution,

- reputation of the manufacturer of the program solution,

- reliability of the program solution,

○ use of reference models,

○ technological completion and modernity

- adoption of the solution to the business practice,

- Project contractor in terms of

- experience in introducing program solutions,

o partnership between the company and the provider (contractor),

o customer confidence in the ability of the project constructor,

- Company which is introducing new IS in terms of

○ support from the top management,

O compliance of the IT and projects with the strategy of the company,

○ wide support for the project,

- transparency of the data and procedures in the organisation,

o levels of the information technology and information knowledge inside the company,

$\circ$ use of modern forms of communication and working in teams,

○ knowledge of project management techniques

- quality of training users,

○ Project duration.

The concept of implementation describes and generally regulates the entire process from initiation through implementation to completion of the project. Given that there are various kinds of information system implementation projects, there are many implementation concepts described in the literature. From classic waterfall model or spiral model to the individual implementation concepts offered by the manufacturer of standard ERP systems.

\section{CONCEPT OF INTRODUCING INFORMATION SYSTEM}

Implementation of the information system is done in two parts.

1. Implementation of the system in the entire company and achieving the basic functionality of the system.

2. System implementation from the achieved level in the first part of the implementation to the desired level using tools to improve business process.

\subsection{The first phase of the information system implementation}

The first part includes the implementation of the system in the entire company in two forms of describing the problem. One form defines phases of introducing a new information system in the company, while the other form defines organizational reference model of the company which is adjusted to the individual needs of the process of that company. This part of introducing information system is divided into five steps:

1. Project management

2. Analysis of existing state

3. Concept development that meets the needs of the company

a. Reference models

b. Models within the ERP system

4. Installation of the information system

5. IS implementation

The project management step is carried out to define objectives, to make project plan, to form project team and to do other activities necessary for the realisation and implementation of the project. The second step, analysis of the existing state, includes the procedure of interviewing and documenting process flows and defining specific values of the measured quantities, which will be further processed through an analysis of the bottleneck in the process. In the third step (concept development that meets the needs of the company) analysed processes are discussed among the project team and a decision is made about the changes that need to take place.

Through the third step „concept development" has been developed reference models. On the one hand, these models can be adjusted to the functionality of the software package and its module. On the other hand, these reference models offer a transparent view of business processes that can be adapted to the individual needs of the company and simultaneously serve as a basic for adapting software to the needs of the company. Another way is to adapt existing business processes to the business processes defined within the standard software solution. Inside of the majority of standard ERP system is integrated big part of a standard business processes with variations which are specifics of the individual industry. This characteristic of the ERP system presents the potential of knowledge embedded in the standard ERP system which can be used in the implementation of the information system.

Parameters of the information system are edited or adjusted in the forth step. The last fifth step is performed to implement software and to do systemic and 
organisational documentation. In the implementation is necessary to pay attention to the order of completion of planned steps to obtain the results of the introduction of a new information system very quickly. Return on investment has a very high priority at this stage. The first part in this fifth step (IS implementation), in addition to the basic ones that are linked to the master data, is warehouse management and processing orders for suppliers, processing customer orders and processing production orders. It is necessary to fully implement this part of implementation. The second part was necessary to optimize the execution of tasks within a particular department. In the third part of the implementation it is necessary to realise functions provided by the software package referring to the statistics, reports and other variables that occur as a result of working with a software package.

\subsection{The second phase of the information system implementation}

After the first phase implementation of the information system it is necessary to move to another part of the implementation using standard tools for business process improvement (Total Cycle time, KAIZEN, Value stream mapping, Six Sigma).

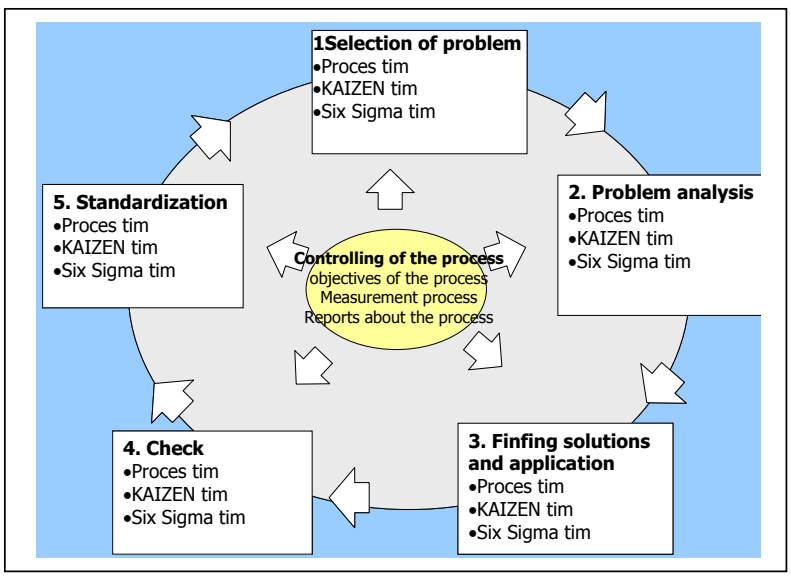

Fig. 3. The second phase of the information system implementation

Company employees are greatly engaged in this part of the implementation of the information system with a minimum involvement of the consultants or programmers. More effects occur during the second step of the information system implementation and simultaneous application of the methods for business process improvement. The first step of the information system implementation sets information and data requirements for establishing a system for controlling processes as a prerequisite for the implementation of the method to improve business process. Implementation of methods for improving business processes will involve all employees to improve business processes, and these improvements will be integrated into the information system which will bring additional quality and speed within business processes. Fig. 4 shows phases of the information system implementation in relation to the efficiency of business processes.

Depending on the degree of the implementation, efficiency of the business process increases over time. Also, without the application of the second phase of the information system implementation there is a drop of efficiency of business processes.

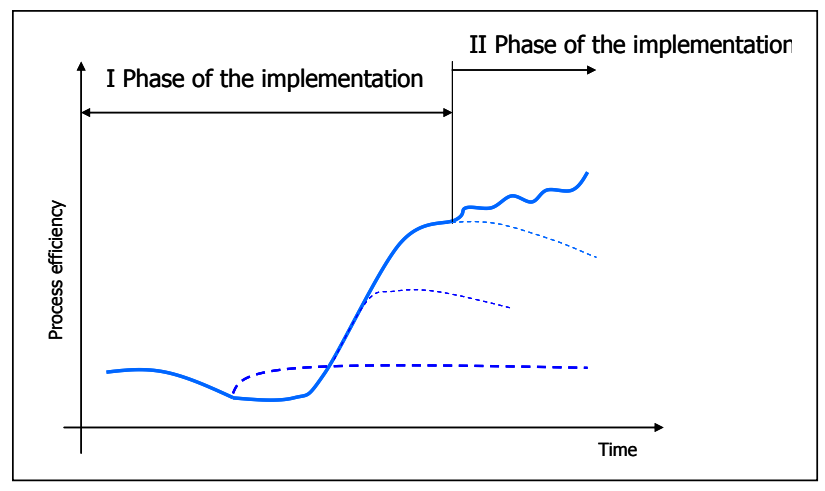

Fig. 4. Phases of the information system implementation

\section{CONCLUSION}

With the proposed concept the company that is introducing new information system from the beginning of the project has an insight into the costs, duration and progression of the project. In addition, company can use the moment of the information system implementation to change and improve business processes and to continuously improve process. This concept makes the introduction of a new information system more transparent and clear, and it is possible to control and achieve the objective of the project. This implementation concept allows parallel improvement of the business processes of the companies and business process automation through the implementation of integrated information systems. Concept allows transparent measurement of the improvement of the business process efficiency caused by the implementation of a new information system. The disadvantage of this methodology is reflected in the implementation time. Implementation time is significantly longer in relation to the standard methodologies. However, greater degree of the utilisation of the chosen software tools is achieved with this method.

\section{REFERENCES}

[1] Allweyer, Th., (2005) Geschäftsprocessmanagement. Strategie, Entwurf, Implementirung, Controling. Herbecke.

[2] Bulinger, H-J. (2003). Neue Organisations-formen im Unternehmen, Springer, 2. Auflage, ISBN 3-540-60263-1, Stuttgart

[3] Broechler, K, Schönberger, C., (2004) Six sigma für den Mittelstand, Campus Verlag Frankfurt/ New York.

[4] Gadatsch, A., (2005) Grundkurs Geschäftsprocessmanagement. Metoden und Werkzeugen für die IT-Praxis, Wiesbaden.

[5] J.Schmelzer H., Sesselmann, W., (2008) Geschäftsprozessmanagement in der Praxis, Hanser Verlag, ISBN 978-3-44641002-2 München.

[6] Martens, P., (2009) Integrierte Informationsverarbeitung 1, Gabler Verlag, ISBN 978-3-8349-1645-7, Wiesbaden

[7] EL Sawy, (1993) Redesigning enterprise processes for eBusiness, McGrow- Hill.

[8] Davenport, T.H. (1993) Proces Inovation: Reenginering Work through Information Technology, Harvard Bysiness School Press.

[9] Hammer M., Champy J. (1993) Reenginering the Corporation: A Manifest for Business Revolution, Harper Business.

[10] Slama D, NeliusEnterprise R. (2011) BPM: Erfolgsrezepte für unternehmensweites Prozessmanagement, dpunkt.verlag. ISBN 9783898646871 , Heidelberg. 